\title{
RESILIÊNCIA FÍSICA DE DOIS LATOSSOLOS VERMELHOS SOB PLANTIO DIRETO(1)
}

\author{
Marina Araújo Bavoso(2), Alvaro Pires da Silva(3) ${ }^{(3) t u l i o ~ C o u t i n h o ~ F i g u e i r e d o(4) ~ C a ́ s s i o ~}$ \\ Antonio Tormena $^{(5)} \&$ Neyde Fabíola Balarezo Giarola(6)
}

\begin{abstract}
RESUMO
A resiliência física de solos é proveniente de processos regenerativos que incluem ciclos de umedecimento e secamento, congelamento e descongelamento, assim como as atividades biológicas. Este estudo testou a hipótese de que as propriedades físicas do solo, como a permeabilidade do solo ao ar, densidade do solo, porosidade de aeração e porosidade total, são indicadores físicos eficientes para quantificar a resiliência de solos de diferentes texturas submetidos ao estresse mecânico (compactação) e após subsequentes ciclos de umedeci mento e secamento. O objetivo foi avaliar o comportamento ea resi liência do solo por meiode propriedades físicas de dois Latossolos Vermel hos. Foram retiradas 25 amostras indeformadas $(0,00$ 0,05 m) de dois solos: solo I, com textura argi losa, e solo II, com textura franco-argiloarenosa, realizando as determinações das propriedades físicas nos tratamentos: antes da compactação (A), depois da compactação (CO) e após ciclos de umedecimento e secamento (C1, C2, C3 e C4). As propriedades densidade do solo e porosidade total não apresentaram recuperação da condição inicial após a compactação nos solos I e II; as propriedades conteúdo volumétrico de água e porosidade deaeração mostraram recuperação parcial apenas no solo I; e a permeabilidade do solo ao ar foi a propriedade que apresentou a melhor recuperação e a maior resiliência. E $\mathrm{m}$ relação ao distinto comportamento dos dois solos, observou-se que o solo I foi mais resiliente que o solo II nas propriedades que apresentaram recuperação.
\end{abstract}

Termos de indexação: permeabilidade do solo ao ar, ciclos de umedecimento e secamento, compactação.

(1) Trabalho extraído da dissertação de mestrado do primeiro autor apresentado à Escola Superior de Agricultura "Luiz de Queiroz", Universidade de São Paulo - ESALQ/USP. Recebido para publicação em 12 de abril de 2012 e aprovado em 03 de outubro de 2012.

(2) Engenheira Agrônoma e Mestre em Ciências, ESALQ/USP. Av. Pádua Dias, 11, Caixa Postal 9. CEP 13418-900 Piracicaba (SP). E-mail: mah.bavoso@gmail.com

(3) Professor Titular, Departamento de Ciência do Solo, ESALQ/USP. E-mail: apisilva@usp.br

(4) Engenheiro Agrônomo e Pós-Doutor pelo Departamento de Ciência do Solo, ESALQ/USP. E-mail: figueiredo.gc@gmail.com

(5) Professor Associado, Departamento de Agronomia da Universidade Estadual de Maringá - UEM, Maringá/PR. Av. Colombo, 5790, CEP 87020-900. Bolsista do CNPq. E-mail: catormena@uem.br

(6) Professor Associado. Departamento de Ciência do Solo e Engenharia Agrícola, Universidade Estadual de Ponta Grossa UEPG. Av. General Carlos Cavalcanti, 4748, CEP 84030-900 Ponta Grossa (PR). E-mail: neydef@uepg.br 


\title{
SUMMARY: PHYSICAL RESILIENCE OF TWO RED OXISOLS UNDER NO- TILLAGE
}

\begin{abstract}
Thephysical resilienceof soil is theresult of regenerativeprocesses with cycles of wetting and drying, freezing and thawing, as well as of biological activities. This study tested the hypothesis that thephysi cal properties of soil such as soil permeability, bulk density, aeration porosity, and total porosity are efficient physical indicators to quantify theresilienceof soils with different textures exposed to mechanical stress (compression) and after subsequent wetting and drying cycles. Theobjective was to evaluatethebehavior and soil resilienceby means of physical properties of an Oxisol. T wenty-fiveundisturbed samples weretaken $(0.00-0.05 \mathrm{~m})$ from two soils: a clayey soil and a soil with sandy clay loam texture, and thephysical properties determined in thetreatments: beforecompression (A), after compaction (C0) and after wetting and drying cycles (C1, C2, C3, C4). Theproperties bulk density and porosity did not return to theinitial condition after compressi on in soil I and II, thevol umetric content of water and airfilled porosity were only partially recovered in soil I, and soil permeability to air was the property with best recovery and resil ience Regarding thedifferent behavior of thetwo soils, it was observed that soil I was moreresilient than soil II in theproperties with recovery.
\end{abstract}

Index terms: soil air permeability, wetting and drying cycles, soil compaction.

\section{NTRODUÇÃO}

As práticas de manejo do solo e das culturas provocam alterações nas propriedades físicas do solo, as quais podem ser permanentes ou temporárias. Assim, o interesse em avaliar a qualidade física do solo tem sido incrementado por considerá-lo um componente fundamental na manutenção e, ou, sustentabilidade dos sistemas de produção agrícola. A qualidade do solo está relacionada à degradaçãoe à resiliência do solo. A resiliência do solo refere-seà sua habilidade em recuperar-se de degradação (ou do estressea quefoi submetido), a qual podeser deorigem antropogênica ou natural, e retornar a um novo equilíbriosemel hanteà condição ou estado antecedente (Seybold et al., 1999).

A mel horia da estrutura do sol o com o avanço do uso do sistema de plantio direto (SPD) tornou-o uma técnica frequente no control e das per das de sol o e de água. No entanto, nos últimos anos, o uso desse sistema tem sido repensado, pois sol os sob esse tipo manejo têm demonstrado problemas de compactação (Klein \& Boller, 1995; Håkansson \& Medvedev, 1995; Silva et al., 2000, 2003; Håkansson, 2005; Silveira et al., 2008; Collares et al., 2008; Reichert et al., 2009), causandoatémesmo oretornoaosistema convencional de preparo do solo (Tormena et al., 1998).

Nessecontexto, al guns agricultores têm mobilizado o sol o utilizando escarificadores (Rosa et al., 2008) e realizando aração e gradagem em solos sob SPD, devido ao surgimento de camadas superficiais $(0,00$ 0,15 m) compactadas (Reichert et al., 2009). Entretanto, na avaliação da compactação, o tempo de adoção do SPD deve ser considerado, visto que as alterações dos atributos físi cos do sol o podem modificar o seu comportamento compressivo ao longo do tempo (Assis \& Lanças, 2005; Silveira et al., 2008). distintos quando el es são submetidos ao processo de compactação. Isso decorre de sua dependência da energia decompactação, da textura, doteor dematéria orgânica, da umi dade do solo e da história de tensão, induzida pel os processos pedogenéticos ou pelo manejo do solo no passado (Dias J unior \& Pierce, 1996), determinando a profundidade de transmissão e a persistência da compactação (Silva et al., 1986; McBride \& Watson, 1990). A compactação do solo geralmentereduza quantidade deágua disponível para as plantas, pois provoca a redução dos macro e dos microporos, levando à dimi nuição da porosidadetotal, o que dificulta o aproveitamento deágua pelas raízes (Brady \& Weil, 2002).

Consi derando os vários aspectos da qualidade do solo (QS), têm-seos componentes ligados à resi stência ou estabilidade do sol o e aquel es ligados à resiliência do sol o. A resistência, segundo Seybold et al. (1999), é a capacidade de o sol o resistir a mudanças causadas por um distúrbio ou, como Lal (1993) a conceitua, éa estabilidade do sol o aos estresses aplicados, referindose diretamente como a suscetibilidade do solo à degradação. Já a resiliência do solo refere-se à habilidade intrínseca do solo em recuperar-se de degradação ou do estresseaplicado, a qual podeser de origem antropogênica ou natural, e retornar a um novo equilíbrio semel hante ao estado antecedente (Blanco\& Lal, 2010). Também pode ser definida como a habilidade do sistema em recuperar sua integridade estrutural efuncional (Seybold et al., 1999).

A resiliência do sol oé uma propriedade dinâmica muito dependente do status do solo na época de aval iação (Seybold et al ., 1999). Gregory et al . (2009) observaram que sol os mais resistentes a estresses são também mais resilientes. Em sistemas agricultáveis, os estresses impostos aos sol os podem ser de origem natural e, ou, antropogênica. Blanco \& Lal (2010) incluem tráfego de máquinas, veículos e animais, 
pastejo inadequado, práticas decultivo emanejo-como o preparo do solo, fertilizações excessivas, irrigação com água de baixa qualidade, aplicação de pesticidas edesmatamento para abertura deáreas -, assi m como o desenvol vimento urbano desordenado e a prática da mineração, como al gumas das causas antropogênicas de perturbação que mais degradam os solos.

Os parâmetros climáticos influenciam na magnitude e na velocidade da capacidade de recuperação dos distúr bios no solo, sendo esta menor em climas secos que em úmidos. Os fenômenos climáticos que alteram a resiliência incluem preci pitação, temperatura, radiação, umidade do ar e demanda evaporativa, al ém de processos ligados ao intemperismo, tempestades, terremotos, fogo, furacões ealagamentos, os quais não são control ados pelo homem. O clima também comanda as atividades biológi cas, corroborando o crescimento mais rápido de plantas em sol os degradados sob clima úmido e temperado que em climas áridos e semiáridos (Lal, 1994).

A resiliência biológica dosol o podeser medida pelas mudanças na mineralização de resíduos de plantas (Griffiths et al., 2000), notamanho ena atividade da biomassa microbiana (Franco et al., 2004). Sob cobertura vegetal o solo é mais resiliente do que quando está nu; quando coberto, os impactos das gotas dechuva são menores, evitando-se a erosão(Vezzani, 2001).

Com fluxo al to de compostos orgânicos, osistema solo tem condições de se auto-organizar em macroagregados com grande capacidade de reter energia e matéria adicionada na forma de C. Nessa condição, há mel horias na resistência à erosão hídrica e eólica; infiltração e retenção de água no solo; sequestro de C; capacidade de retenção de cátions; aumento do estoque de nutrientes; adsorção e complexação de compostos orgânicos e inorgânicos; favorecimento da biota do sol o; promoção da ciclagem dos elementos químicos; eresistência a perturbações e aumento da resiliência. Quando a magnitude do fluxo é baixa, o sistema solo se auto-organiza em estados de ordem menores e mais simples (microagregados). Nessa condição, o sol o perde sua habilidade para exercer suas funções e tem sua qualidade reduzida (Vezzani, 2001).

A resiliência física vem de uma variedade de processos regenerativos que incluem ciclos de umedecimento e secamento, congelamento e descongel amento, assim comoas atividades biológicas, como o crescimento de raízes e a atividade da fauna edáfica, quetambém influenciama resiliência química e biológica (Seybold et al., 1999; Gregory et al., 2007).

Neste trabalho, a hipótese avaliada é de que as propriedades físicas, como porosidades total e de aeração, conteúdovolumétrico deágua, teor decarbono orgânico, permeabilidade ao ar e densidade do solo, são indicadoras do estado da qualidade e, ou, da resiliência de sol os sob plantio direto. Assim, o objetivo foi avaliar a qualidade ea resiliência do solo o partir da mensuração dessas propriedades físicas de dois Latossolos Vermelhos, de diferentes texturas e em distintos estados de compactação e intensidades de ciclos de umedecimento esecamento.

\section{MATERIALEMÉTODOS}

As amostragens foram realizadas na Fazenda Escola Capão da Onça, pertencente à Universidade Estadual dePonta Grossa ( $25^{\circ} 05^{\prime} 47^{\prime \prime}$ delatitude sul; $50^{\circ} 03^{\prime} 11^{\prime \prime}$ de longitude oeste), local izada no município de Ponta Grossa - PR. A altitude média da região éde $1.025 \mathrm{~m}$, sendo o clima classificado como subtropical úmidomesotérmico (Cfb). A precipitaçãopluvial média anual é de $1.545 \mathrm{~mm}$, ea temperatura média anual, de $18,7^{\circ} \mathrm{C}$ (Caviglioneet al., 2000).

O experimento foi definido como um "on farm research", ondeas áreas deestudo foram del imitadas dentro das áreas de produção. A amostragem foi realizada em maio/2010, entre as safras de verão e inverno; portanto, as culturas de inverno não haviam sido semeadas eas de verão tinham sido col hidas em abril. Essas áreas possuem histórico de rotação de culturas há 15 anos, que incluem culturas de verão, como milho (Zea mays L.), soja (Glycine max L.) e feijão (Phaseol us vul garis L.), eculturas de inverno, como trigo (Triticum aestivum L.), aveia-preta (Avena strigosa Schreb) e ervilhaca (Vicia sativa L.).

Foram delimitadas duas áreas de amostragem, em dois Latossolos Vermelhos, sendo o solo I de textura argil osa (501 $\mathrm{g} \mathrm{kg}^{-1}$ de argila , $75 \mathrm{~g} \mathrm{~kg}^{-1}$ de siltee $424 \mathrm{~g} \mathrm{~kg}^{-1}$ de areia) eo sololl de textura francoargilo-arenosa ( $226 \mathrm{~g} \mathrm{~kg}^{-1}$ deargila, $32 \mathrm{~g} \mathrm{~kg}^{-1}$ de silte e $742 \mathrm{~g} \mathrm{~kg}^{-1}$ de areia). A textura foi determinada pelo método do hidrômetro (Gee\& Bauder, 1986).

De cada solo foram retiradas 25 amostras indeformadas, utilizando anéis volumétricos de $96,2 \mathrm{~cm}^{3}(7,0 \times 2,5 \mathrm{~cm})$ e um dispositivo el etromecânico (Figueiredo, 2010), com o objetivo de melhorar a qualidade da amostragem pela não aplicação de percussão. Os pontos de amostragem foram aleatórios, sendo descartadas áreas marginais. A profundidade deamostragem correspondeu ao centro da camada superficial de 0-5 cm. Realizou-setambém a retirada de uma amostra composta de cada sol o.

As amostras indeformadas foram preparadas no Laboratório de Física do Solo da ESALQ/USP, retirando-se o excesso de sol o das extremi dades das amostras, de modo que o vol ume de sol o equival esse às dimensões do anel.

Estabeleceu-seo primeirotratamento, denominado de- antes da compactação (A) - ondeas amostras foram saturadas com água por capilaridade durante $24 \mathrm{~h}$, submetidas ao potencial mátrico de-10 kPa durante $24 \mathrm{~h}$, em uma mesa detensão descrita por Ball et al . 
(1988), e pesadas; foram feitas medições de permeabilidade do solo ao ar $\left(k_{a}\right)$, por meio de permeâmetro portátil de carga constante de ar, desenvolvido por Figueiredo (2010), cujo princípio de funcionamento consistena utilização de uma amostra de solo, confinada em anel volumétrico e com livre fluxo de gases em suas extremidades, a qual é submeti da a incrementos sucessivos e constantes de taxas defluxo dear, gerando gradientes de pressão. $O$ permeâmetro possui um reservatório de ar comprimido, com a finalidade de fornecer gás sob pressão maior que a atmosférica ao sistema pneumático do permeâmetro. Adicionalmente, o equipamentotambém possui um controlador devazão mássica de gases com medidor el etrônico do processo, quemantém uma vazão de ar constante e predefinida entre 0 e $20 \mathrm{~mL} \mathrm{~min}^{-1}$, a qual atravessa uma determinada amostra desolo.

Estabel ecendo-se um determinado fluxo dear ea respectiva diferença de potencial necessária para que esse fluxo transpasse uma amostra ea partir da Lei de Darcy, a densidade de fluxo de ar (q) pode ser descrita como:

$$
q=-\frac{k_{a}}{\eta}\left(\frac{d P}{d Z}+\rho g\right)
$$

sendo $q[L / T], k_{a}\left[L^{2}\right], P$ a pressão de $\operatorname{ar}\left[M / L T^{2}\right] ; Z, a$ distância $[L]$ na direção do movimento dear nosistema poroso; $\eta$, a viscosidade do ar [M/LT]; $\rho$, a densidade do ar [M/L $\left.{ }^{3}\right] ;$ eg, a acel eração da gravidade $\left[L / T^{2}\right]$. A densidade de fluxo correspondeà vazão dear (Q) $\left[L^{3} /\right.$ $T$ ] por área perpendicular ao movimento do fluido $\left(A_{s}\right)$ [ $L^{2}$ ]; considerando como desprezível a influência da densidade do ar (Springer et al., 1995), a equação (2) foi utilizada para as estimativas da $\mathrm{k}_{\mathrm{a}}$ :

$$
\mathrm{k}_{\mathrm{a}}=\frac{\mathrm{Q} \eta}{\mathrm{A}_{\mathrm{s}}}\left(\frac{\mathrm{dZ}}{\mathrm{dP}}\right)
$$

A medida deZ decada amostra foi considerada no tratamento $A$ igual à altura do anel $(0,025 \mathrm{~m})$.

No segundo tratamento, as amostras foram novamentesaturadas por capilaridade durante $24 \mathrm{~h}$ e submetidas ao potencial mátrico de $-10 \mathrm{kPa}$ em mesa detensão durante $24 \mathrm{~h}$; realizou-se em seguida a compressão uniaxial, que consistiu na aplicação contínua deuma pressão preestabelecida de $200 \mathrm{kPa}$, por meio da aplicação de uma força vertical de 76,28 kgf sobre amostra, em um sistema de consolidação e aquisição de dados automatizados (marca Satron, modelo MCT 2000, MIRAE Engineering I nc., Buscan Korea ${ }^{\circledR}$ ). Essa força simula um estresse típico de compactação em campo; por exemplo, a pressão exercida por um pneu de trator em um estudo de compactação em campo descrito por Gregory et al. (2007) foi igual a 180 kPa. A pressão foi aplicada por $5 \mathrm{~min}$, conformesugerido por Silva et al., 2000.

Posteriormente ao ensaio de compressão uniaxial, as amostras foram novamente saturadas por $4 \mathrm{~h}$ e, então, submetidas ao potencial mátrico de-10 kPa em mesa detensão durante $24 \mathrm{~h}$; foram realizadas pesagens e, imediatamente, medições de $k_{a}$ - este segundo tratamento foi chamado de pós-compactação- C0.

A medida de $Z$, utilizada na determinação da permeabilidade do solo ao ar, para o tratamento C0 foi aferida consi derando a diferença entrea altura do anel ea superfíciesuperior dosolo; para isso, foi utilizado um micrômetro digital (marca Digimess ${ }^{\circledR}$ ), com capacidade de 0-25 mmeresolução de 0,001 mm, eum disco metálico de $0,7 \mathrm{~mm}$ de espessura ediâmetro de $50 \mathrm{~mm}$, colocado entreas superfícies dosoloe da haste de medi ção do micrômetro com o objeti vo mel horar a quantificação da deformação do solo, já queo diâmetro da haste de medição é relativamente diminuto em relaçãoao da amostra desolo, o que poderia incrementar os erros sistemáticos das medições.

Na sequência, iniciou-seumcido deumedecimento e secamento, conforme indicações de Gregory et al . (2009). Esse procedimento consistiu em umedecimento das amostras com água por capilaridade durante $3 \mathrm{~h}$; drenagem em mesa detensãoao potencial mátrico de $-0,5 \mathrm{kPa}$ durante $24 \mathrm{~h}$; secagem em estufa a $40^{\circ} \mathrm{C}$ por $24 \mathrm{~h}$; umedecimento com água por capilaridade durante $12 \mathrm{~h}$; drenagem ao potencial mátrico de-10 kPa por 24 h; pesagem; e medição de $k_{a}$. Na medição de $_{a}$ considerou-sea medida de Z, conforme descrito para C0. Este tratamento foi denominado primeiro ciclo (C1). Foram realizados mais três tratamentos repetindo os procedimentos de $\mathrm{C} 1$, os quais foram denominados: segundo ciclo (C2), terceirociclo(C3) e quarto ciclo (C4). Em resumo, a sequência dos tratamentos e os respectivos procedimentos são mostrados no quadro 1 . Os cidos foram procedimentos padronizados erealizados em sequência.

Com os dados de pesagem e vol ume de solo, para cada tratamento, foram determinadas a densidade do solo $\left(\rho_{\mathrm{s}}\right)$, em $\mathrm{g} \mathrm{cm}^{-3}$ (Blake \& Hartge, 1986), e a umi dade vol umétrica $(\theta c c)$, obtida por:

$$
\theta=\left(\frac{\rho_{s}}{\rho_{a}}\right) \times U
$$

em que $\rho$ éa densidade da água $\left(\mathrm{g} \mathrm{cm}^{-3}\right)$ eU a umidade gravimétrica em $\mathrm{g} \mathrm{g}^{-1}$, conformeGardner (1986).

A porosidade total do solo $(\alpha)$, em $\mathrm{cm}^{3} \mathrm{~cm}^{-3}$, a porosidadelivredeágua ou porosidade deaeração $\left(\varepsilon_{a}\right)$,

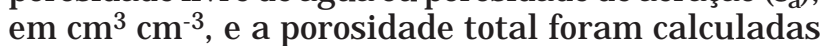
segundo Libardi (2005).

As amostras passaram por secagem em estufa a $105^{\circ} \mathrm{C}$ por $24 \mathrm{~h}$, para obtenção da massa de sol o seco. Com a amostra composta de cada solo, determinou-se o carbono orgânico (CO) pel o método de combustão via seca, utilizando um analisador elementar (Thermo ${ }^{\circledR}$ Flash EA 1112), ondea medida do C do solo ébaseada na quantificação do $\mathrm{CO}_{2}$ por infravermelho médio, sendo o $\mathrm{CO}_{2}$ formado pela oxidação dos constituintes orgânicos da amostra. Para a quantificação da densidade de partícula (Dp), 


\section{Quadro 1. Descrição dos tratamentos aplicados aos dois Latossolos Vermelhos distróficos sob plantio direto}

\begin{tabular}{|c|c|c|}
\hline Etapa & Tratamento & Sequência de procedimento \\
\hline 1 & Antes da compactação (A) & Saturação $^{(1)}$, drenagem ${ }_{-10 \mathrm{kPa}}$, pesagem, medição de ka ${ }^{(2)}$ \\
\hline 2 & Pós-compactação (C0) & Compactação(3) , saturação(1) drenagem $_{-10 \mathrm{kPa}}$, pesagem, medição de ka \\
\hline 3 & 1으이 (C1) & $\begin{array}{l}\text { U medecimento }{ }^{(4)} \text {, drenagem } \\
-0,5 \mathrm{kPa}, \text { secagem }_{40}{ }^{\circ} \mathrm{C}, \text { umedecimento }{ }^{(5)} \text {, drenagem } \\
\text { pesagem, medição de ka }\end{array}$ \\
\hline 4 & 2o Ciclo (C2) & $\begin{array}{l}\text { Umedecimento }^{(4)} \text {, drenagem } \\
\text { pesagem, medição de ka }\end{array}$ \\
\hline 5 & 3o Ciclo (C3) & $\begin{array}{l}\text { U medecimento }^{(4)} \text {, drenagem } \\
\text { pesagem, medição de } \mathrm{ka}\end{array}$ \\
\hline 6 & 4 o Ciclo (C4) & $\begin{array}{l}\text { Umedecimento }^{(4)} \text {, drenagem } \\
\text { pesagem, medição de } \mathrm{ka}\end{array}$ \\
\hline
\end{tabular}

Drenagem $_{-10 \mathrm{kPa}}$, amostras equilibradas no potencial mátrico de -10 kPa durante $24 \mathrm{~h}$; Drenagem-0,5kPa, amostras equilibradas no potencial mátrico de -0,5 kPa durante $24 \mathrm{~h}$; Secagem ${ }_{40}{ }^{\circ} \mathrm{C}$, amostras secas em estufa a $40^{\circ} \mathrm{C}$ durante $24 \mathrm{~h}$. ${ }^{(1)} \mathrm{Amostras}$ umedecidas com água, por capilaridade, durante $24 \mathrm{~h}$; (2) ka é a permeabilidade do solo ao ar; ${ }^{(3)}$ Amostras submetidas à compressão uniaxial de $200 \mathrm{kPa}$ durante $5 \mathrm{~min}$; ${ }^{(4)}$ Amostras umedecidas com água, por capilaridade, durante $3 \mathrm{~h} .{ }^{(5)}$ : Amostras umedecidas com água, por capilaridade, durante $12 \mathrm{~h}$.

retirando-seuma alíquota desol o deterra fina, a qual foi seca em estufa, utilizando ométodo de deslocamento de gás através de um picnômetroa gás Hélio (modelo ACCUPYC 1330, marca Micrometrics Instrument Corporation ${ }^{\circledR}$; partindo do princípio de um volumee massa conhecidos, foram processados $8 \mathrm{~g}$ de cada amostra composta em triplicata.

Os índices de resiliência do solo (taxa de recuperação) foram calculados para as propriedades densidade do solo $\left(\rho_{s}\right)$, conteúdo vol umétrico deágua, porosidades total e deaeração e permeabilidade dosolo ao ar, segundo Herrick \& Wander (1998), pela seguinte equação:

$$
\text { Resiliência (recuperação) }=(B-C) /(A-C)
$$

em que $A$ éa capacidade do solo de funcionar em prédistúrbio (antes da compactação - tratamento A); B , o nível derecuperação (medido após o quarto cido- C4); eC, o nível defuncionamento do solo imediatamente após o distúr bio (após a compactação- tratamento C0).

Pela condução diferenciada do experimento, adotouseo interval o de confiança da média $85 \%$ como critério para discriminação e comparação dos tratamentos, considerando que houvediferença significativa quando não ocorreu sobreposição dos limites superior einferior. O intervalo deconfiança representa os limites em que a média dos valores de um conjunto de dados está contida vem a ser útil econfiável para a interpretação de diferenças significativas (Payton et al., 2000).

\section{RESULTADOS E DISCUSSÃO}

Os val ores médios dos teores de carbono orgânico (CO) (Quadro2) não diferiram entre os sol os $(p>0,05)$ pel otestet. Esses resultados podem ser justificados
Quadro 2. Valores médios dos atributos físicos de dois Latossolos Vermelhos distróficossob plantiodireto

\begin{tabular}{lcc}
\hline \multirow{2}{*}{ Atributo } & \multicolumn{2}{c}{ Solo } \\
\cline { 2 - 3 } & I & I I \\
\hline Areia, g kg & 424 & 742 \\
Silte, $\mathrm{g} \mathrm{kg}^{-1}$ & 75 & 32 \\
Argila, g kg-1 & 501 & 226 \\
Carbono Orgânico, \% & 3,80 & $4,30 \mathrm{~ns}$ \\
Densidade de partícula, $\mathrm{Mg} \mathrm{m}^{-3}$ & 2,56 & $2,58 \mathrm{~ns}$ \\
\hline
\end{tabular}

ns= não significativo a $5 \% ; N=25$.

pel o fato de que ambos os sol os vêm sendo manejados sob plantio direto com rotação deculturas eas práticas de manejo utilizadas seguem os preceitos de manutenção de resíduos sobre a superfície e não revolvimento dosolo.

Os valores de densidade de partícula (Dp) encontrados também não di feriram entresi $(p>0,05)$. Esse atributo do sol o possui grande estabilidade por ser dependente das proporções relativas das frações mineral e orgânica, assim como da composição mineralógica dos solos, e encontra-se dentro da faixa em que se enquadra a maior parte dos solos mi nerais: de 2,6 a 2,75 $\mathrm{Mg} \mathrm{m}^{-3}$ (Brady \& Weil, 2007).

No quadro 3 são apresentados os resultados da análise estatística descritiva para a densidade do solo $\left(\rho_{\mathrm{s}}\right)$. Os valores do solol variaram de 0,99 a $1,40 \mathrm{~g} \mathrm{~cm}^{-3}$, e os do solo II, de 1,07 a 1,55 $\mathrm{g} \mathrm{cm}^{-3}$, apresentando baixa variabilidade, sendo o coeficiente de variação (CV) em torno de $6 \%$ para ambos os solos. Val ores de CV inferiores a $15 \%$, conforme Warrick (1998), são normalmente encontrados para essa propriedade, assim como os valores médios de $1,27 \mathrm{~g} \mathrm{~cm}^{-3}$ para 0 solo I e 1,38 $\mathrm{g} \mathrm{cm}^{-3}$ para o solo II. Esses resultados 
concordam com os de Cavalieri et al. (2009) e Figueiredo et al. (2011) para Latossolos Vermel hos dessa região, similares ao do presente estudo.

O conteúdo de água no sol o apresentou valores médios de 0,39 e $0,28 \mathrm{~cm}^{3} \mathrm{~cm}^{-3}$, respectivamente para os solos I ell. A porosidadetotal foi em média de $0,50 \mathrm{~cm}^{3} \mathrm{~cm}^{-3}$ no sol ol e $0,47 \mathrm{~cm}^{3} \mathrm{~cm}^{-3}$ no sololl, com variação em torno de $6 \%$ emambos os solos. A variável porosidade de aeração apresentou CV de 33,69\% para osolo I, porque osoloargiloso mostrou drenagem mais Ienta; já o sololl apresentou CV de 7,28\%(Quadro 3).

$A k_{a}$, por setratar de uma propriedade dinâmica, foi altamente variável, como indica o coeficiente de variação de 109,02 \% para o solo l e 78,70 \% para o sololl, valores estes elevados, assim como em Cavalieri et al . (2009) (Quadro 3).

Na figura 1, observa-se que em ambos os solos houvediferença significativa dedensidadedosol oentre o tratamento A e os demais; após a compactação, a densidademanteve-sepraticamenteconstante.

Em relaçãoaos valores de densidade restritivos ao crescimento de raízes, considerados para solos argi losos entre 1,3 e 1,4 $\mathrm{g} \mathrm{cm}^{-3}$ (Reichardt et al., 2003) e para sol os arenosos acima de $1,75 \mathrm{~g} \mathrm{~cm}^{-3}$ (Corsini \& Ferraudo, 1999), observa-se que as amostras não apresentaram valores de $\rho_{s}$ el evados após a compactação, enquadrando-se abaixo dos limites restritivos.

Os estresses induzidos aumentaram a $\rho_{\mathrm{s}} \mathrm{e}$ alteraram a sua estrutura, mesmo após C4, por se tratar de uma propriedade de difícil recuperação após um distúrbio; a $\rho_{\mathrm{s}}$ não recuperou sua condição inicial, não sendo, portanto, influenciada pelos ciclos de umedecimento e secamento. Essa condição de incremento da $\rho_{\mathrm{s}}$ após a compactação- observada em ambos os sol os, mensurada pel oíndice de resiliência

Quadro 3. Momentos estatísticos para os atributos físicos de dois Latossolos Vermelhos distróficos sob plantio di reto, um argi loso (solo I ) e um franco-argi lo-arenoso (solo II)

\begin{tabular}{|c|c|c|c|c|c|c|c|}
\hline Atributo & Solo & Mínimo & Máximo & Média & Mediana & $D P^{(6)}$ & CV(\%) \\
\hline \multirow[t]{2}{*}{$\rho_{\mathrm{s}}\left(\mathrm{g} \mathrm{cm}^{-3}\right)^{(1)}$} & I & 0,99 & 1,40 & 1,27 & 1,30 & 0,09 & 6,31 \\
\hline & II & 1,07 & 1,55 & 1,38 & 1,39 & 0,11 & 6,38 \\
\hline \multirow[t]{2}{*}{$\theta \mathrm{cc}\left(\mathrm{cm}^{3} \mathrm{~cm}^{-3}\right)^{(2)}$} & I & 0,34 & 0,45 & 0,39 & 0,39 & 2,15 & 4,35 \\
\hline & II & 0,20 & 0,39 & 0,28 & 0,28 & 3,17 & 10,49 \\
\hline \multirow[t]{2}{*}{$\alpha\left(\mathrm{cm}^{3} \mathrm{~cm}^{-3}\right)^{(3)}$} & I & 0,45 & 0,61 & 0,50 & 0,49 & 3,57 & 6,22 \\
\hline & II & 0,40 & 0,59 & 0,47 & 0,46 & 4,13 & 6,38 \\
\hline \multirow[t]{2}{*}{$\varepsilon_{\mathrm{a}}\left(\mathrm{cm}^{3} \mathrm{~cm}^{-3}\right)^{(4)}$} & I & 0,02 & 0,26 & 0,11 & 0,11 & 4,41 & 33,69 \\
\hline & II & 0,08 & 0,39 & 0,19 & 0,18 & 6,10 & 7,28 \\
\hline \multirow[t]{2}{*}{$k_{a}\left(\mu m^{2}\right)^{(5)}$} & I & 0,10 & 79,69 & 14,29 & 7,76 & 16,91 & 109,02 \\
\hline & II & 0,74 & 75,60 & 13,28 & 9,42 & 11,99 & 78,70 \\
\hline
\end{tabular}

(1)Densidade do solo; (2)Conteúdo volumétrico de água do solo na capacidade de campo; ${ }^{(3)}$ Porosidade total do solo; ${ }^{(4)}$ Porosidade de aeração do solo; ${ }^{(5)}$ Permeabilidade do solo ao ar; ${ }^{(6)} \mathrm{DP}$ : desvio-padrão; $\mathrm{N}=25$.

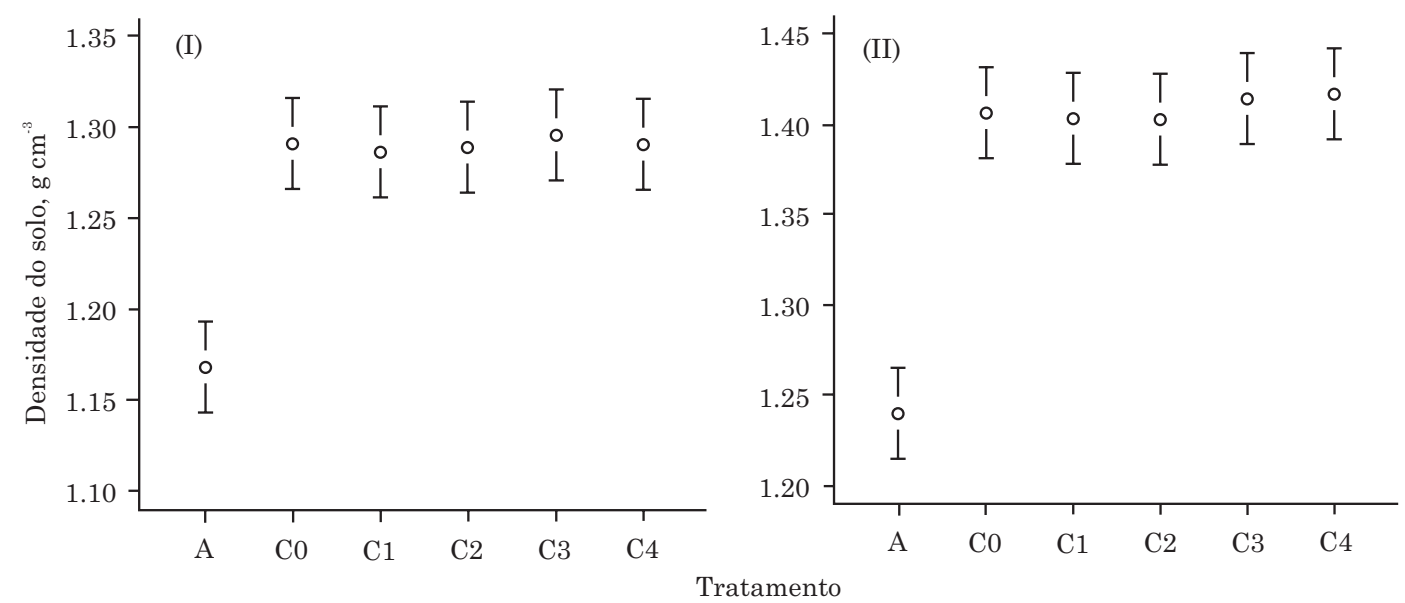

Figura 1. Valores médios de densidade de dois Latossol os Vermelhos distróficos, um argiloso (I ) e um francoargilo-arenoso (II ), nos tratamentos A, C0, C1, C2, C3eC4. As barras representam o interval o de confiança da média (85\%). 
(Figura 2) - apresentou val ores médios próximos a zero, o que demonstra que, quando alterada, a $\rho_{\mathrm{s}}$ necessita de práticas de manejo etempo maior de recuperação.

Alguns autores relatam aumento da densi dade de sol os sob plantio dir eto devidoà compactação causada pelo tráfego de máquinas e ao seu não revolvimento (Håkansson et al., 1988; Streck et al., 2004; Giarola et al., 2009), ocasionando um rearranjo das partículas, o que podeser evidenciado em ambos os solos, pois a $\rho_{\mathrm{s}}$ permaneceu com valores mais elevados após a compactação mesmo quando exposta à força dos ciclos de umedecimento esecamento (Figura 1).

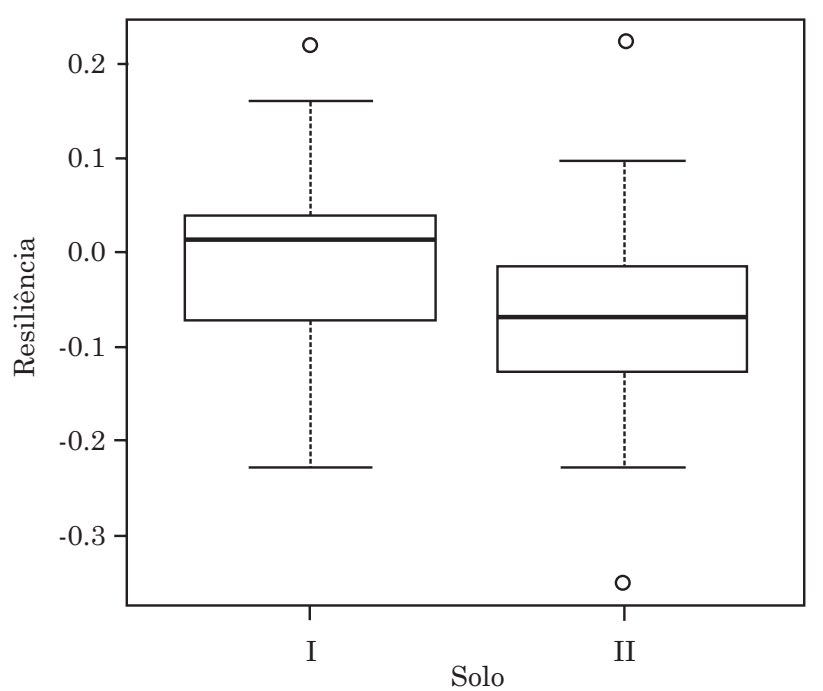

Figura 2. Distribuição dos índices de resiliência da densidade de dois Latossolos Vermelhos distróficos, um argiloso (I) e um franco-argiloarenoso (II). As barras representam o intervalo de confiança da média ( $85 \%$ ).
A retenção de água foi alterada pela compactação das amostras em ambos os sol os (F igura 3). Observase que o conteúdo vol umétrico de água nas amostras dosolol mostrou diferença significativa dotratamento C0 em relação aos demais, ou seja, na condi ção após a compactação apresentou incremento, al cançando valores médios em torno de $0,41 \mathrm{~cm}^{3} \mathrm{~cm}^{-3}$. Nos tratamentos $\mathrm{C} 1$ a C4, observa-se que o conteúdo vol umétrico de água retorna a valores semel hantes aos da condição inicial, representada pel otratamento A, antes da compactação.

No solo II houve diferença significativa do tratamento A em relação aos demais; após a compactação esse sol o apresentou val ores médi os de conteúdo volumétrico deágua mais el evados (emtorno de $0,28 \mathrm{~cm}^{3} \mathrm{~m}^{-3}$ ) e permaneceu após os ciclos de umedecimento e secamento (Figura 3).

O comportamento distinto dessa variável nos dois sol os deve-seà maior capacidade de retenção deágua nos sol os com mai or teor de argila, os quais possuem maior área superficial emicroporosidade, retendoágua na forma de pequenos filmes aderidos à superfície das partículas do solo (Roseberg \& M cCoy, 1992; Brady \& Weil, 2002).

O solol apresentou índices de resiliência próximos a 3, e o solo II, valores negativos (Figura 4), o que demonstra a maior resiliência do primeiro; provavelmente, devido ao maior teor de argila, no processo de umedecimento haja maior retenção de água mesmo após a compactação (Dexter, 1991).

Os val ores de porosi dade de aeração $\left(\varepsilon_{a}\right)$ (Figura 5) demonstraram que no solo I há recuperação significativa após $\mathrm{Cl}$ em relaçãoa $\mathrm{C0}$, porém os valores nãoalcançamo estado inicial A. No sololl não houve recuperação após C0; a redução significativa da $\left(\varepsilon_{\mathrm{a}}\right)$ do tratamento $A$ em relação aos demais não foi recuperada nos demais tratamentos. Essa recuperação
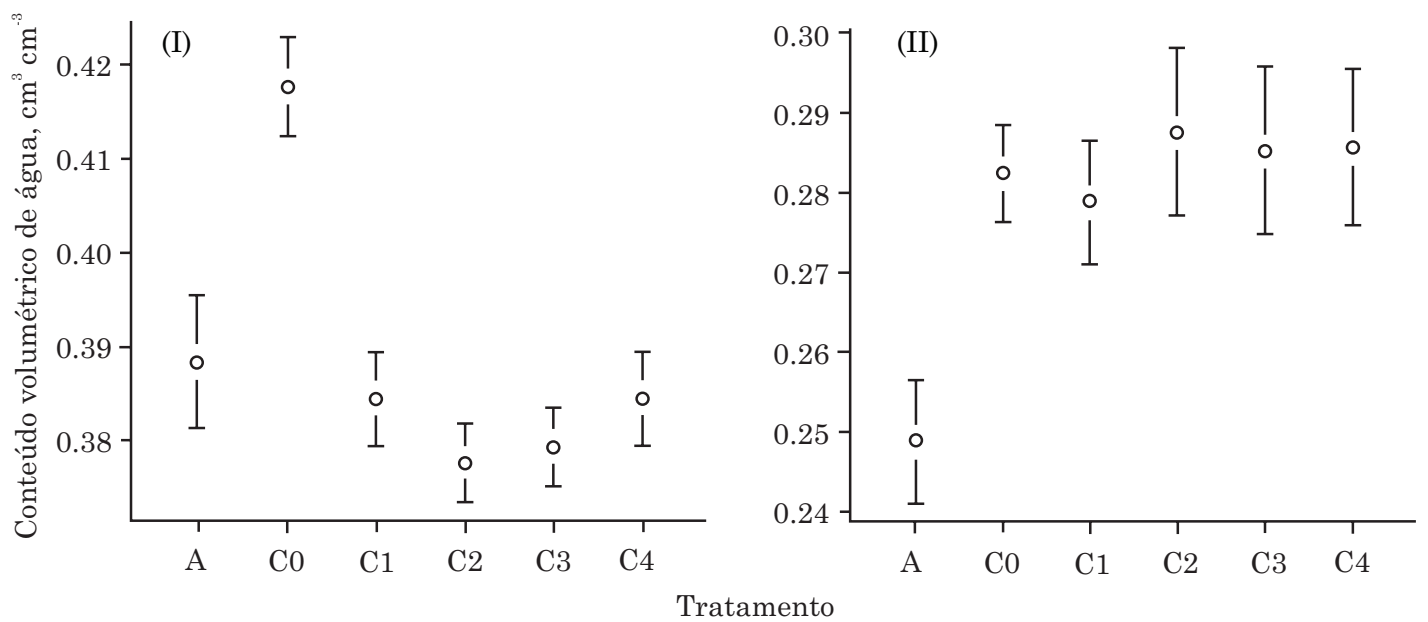

Figura 3. Valores médios de conteúdo volumétrico de água de dois Latossolos Vermelhos distróficos, um argiloso (I) e um franco-argil lo-arenoso (II), nos tratamentos A, C0, C1, C2, C3e C4. As barras representam o intervalo de confiança da média ( $85 \%$ ). 
parcial da $\left(\varepsilon_{\mathrm{a}}\right)$ após os ciclos de umedecimento e secamento demonstra que solos com maior teor de argila apresentam maior resiliência em relação à estrutura porosa do solo que aquel es mais arenosos.

Segundo Chan (2002), valores de $\varepsilon_{\mathrm{a}}$ entre 0,05 e $0,15\left(\mathrm{~m}^{3} \mathrm{~m}^{-3}\right)$ podem ser comumente usados como limites críticos; abaixo desse intervalo a aeração é insuficiente para o crescimento das raízes. Neste estudo foram observados val ores médi os para o solol em torno de 0,07 $\mathrm{cm}^{3} \mathrm{~cm}^{-3}$ em C0; portanto, o crescimento das raízes poderia ser limitado pela baixa aeração.

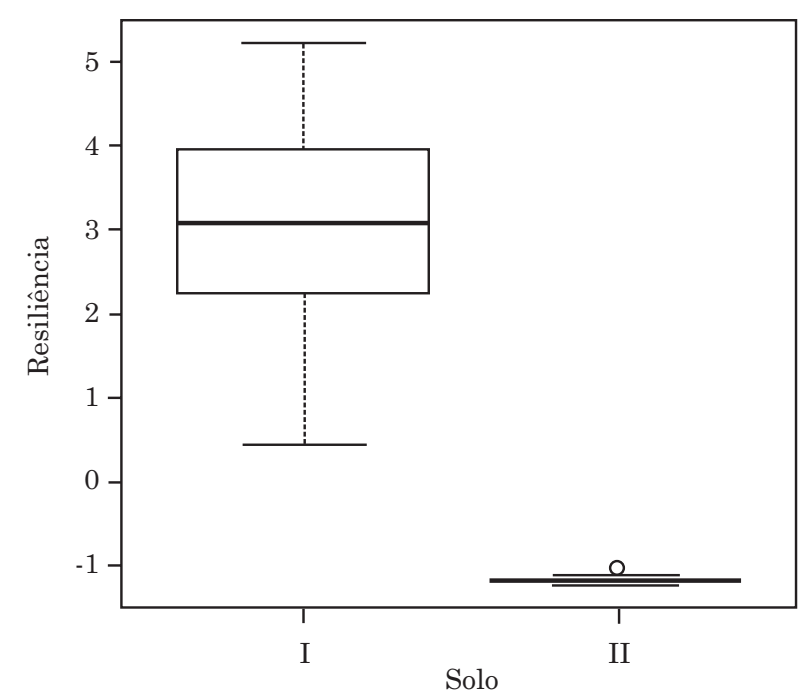

Figura 4. Distribuição dos índices de resiliência do conteúdo volumétrico de água de dois Latossolos Vermelhos distróficos, um argiloso (I) e um franco-argilo-arenoso (II). As barras representam o intervalo de confiança da média (85\%).

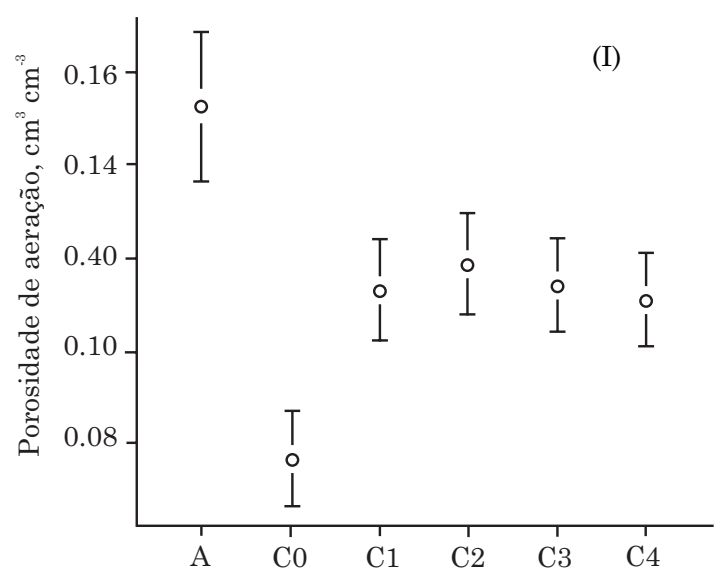

Figura 5. Valores médios de porosidade de aeração de dois Latossolos Vermelhos distróficos, um argi loso (I) e um franco-argilo-arenoso (II), para os tratamentos A, CO, C1, C2, C3 e C4. As barras representam o intervalo de confiança da média (85\%).

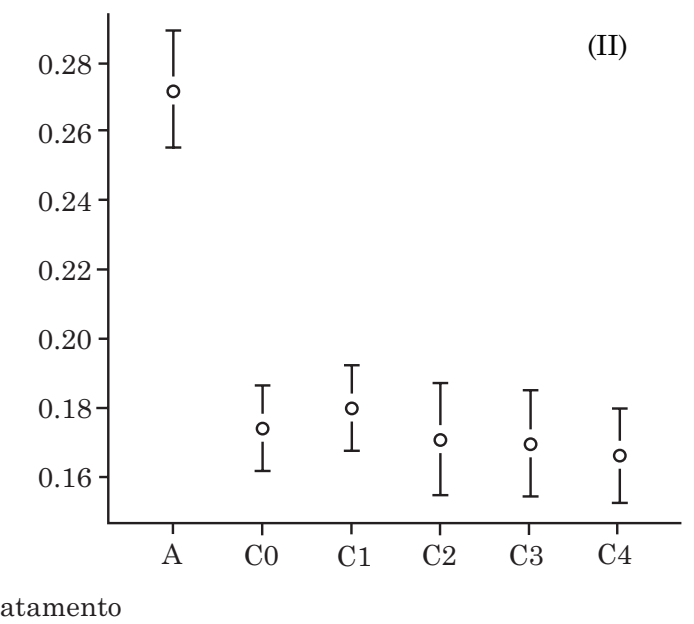

Assim como o conteúdo volumétrico de água, a capacidade de recuperação da porosidade de aeração dosolo está diretamenterelacionada com a capacidade deagregação, quefavorecea reorganização dosistema poroso a partir de um impacto hidráulico (Horn \& Baumgartl, 2002). Esse impacto causado pel os ciclos de umedecimento esecamento, ou seja, dependendo das al terações no conteúdo de água no solo, al iado ao manejo, faz com que a estrutura do solo, bem como suas propriedades relacionadas ao sistema poroso, comoíndice devazios (Dörner et al ., 2009), capacidade de aeração, condutividadehidráulica e resistência a penetração (Dec et al., 2011), apresentem comportamento dinâmico e mudem temporária e espacialmente.

J á a reduçãosignificativa na porosidadetotal (PT) nos sol os I ell após a compactação(C0), em relaçãoao tratamento A (Figura 6), pode ser explicada pel o fato de os macroporos sofrerem maior redução e consequente aumento dos microporos quando submetidos a estresses mecânicos, reduzindo a porosidadetotal (Araújo, 2004).

Não há recuperação da PT mesmo após os ciclos de umedecimento e secamento ( $\mathrm{Cl}$ a C4); assim, podeseafirmar quea PT dos solos dependenteda estrutura émuitovulnerável aos estresses mecânicos, conforme salientado por Baumgartl \& Köck (2004).

O índice de resiliência próximo a zero demonstra que a PT e a $\varepsilon_{a}$ não apresentaram recuperação portanto, foram alteradas pela compactação-eos cidos de umedecimento e secamento não foram suficientes para oretorno à condição inicial .

Os dados de $k_{a}$ foram ajustados às distribuições mais próximas da normal idade, por meio da aplicação dologaritmo dek $k_{a}$, visto que a distribuição dos valores de $k_{a}$ para os dois solos avaliados apresentou-se assimétrica e não normal usando o teste de Shapiro

Tratamento 


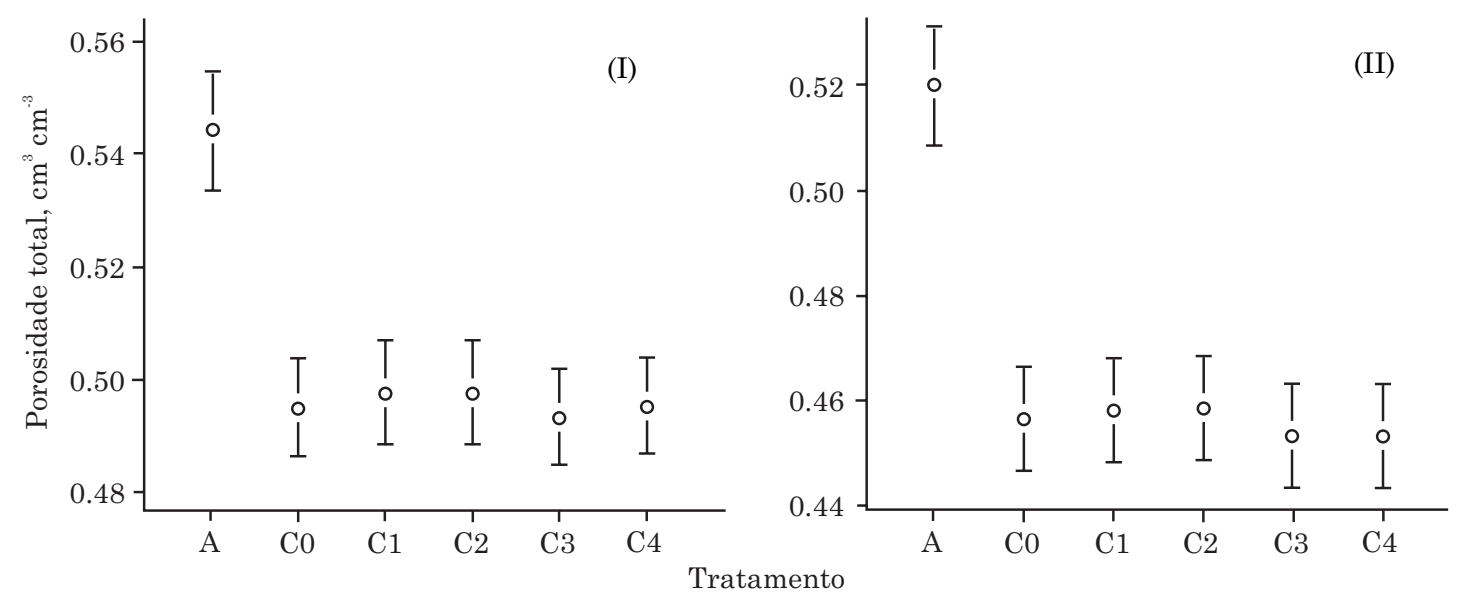

F igura 6. Valores médios de porosi dade total de dois Latossolos Vermel hos distróficos, um argi loso (I ) e um franco-argi lo-arenoso (II ), nos tratamentos A, C0, C1, C2, C3 e C4. As barras representam o intervalo de confiança da média ( $85 \%)$.
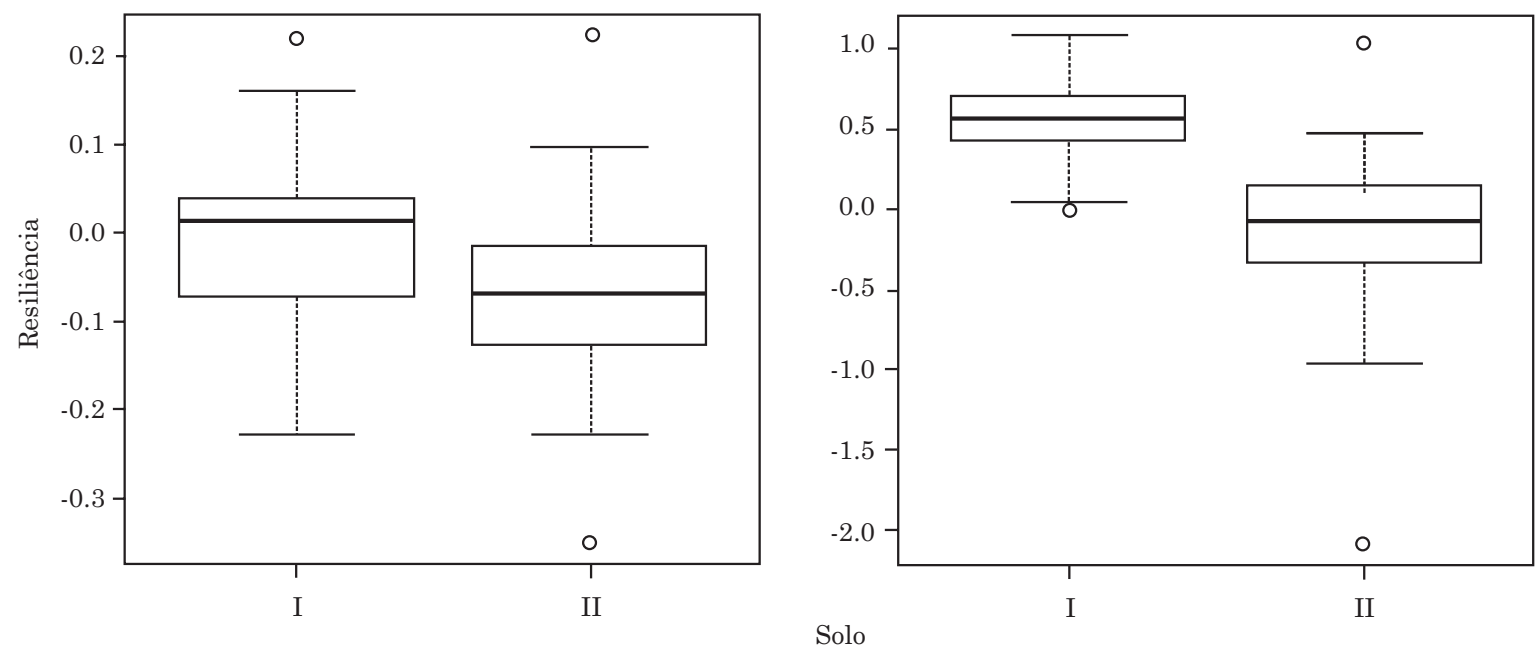

Figura 7. Distribuição dos índices de resiliência da porosidade total e de aeração dois Latossolos Vermel hos distróficos, um argi loso (I ) e um franco-argi lo-arenoso (II ). As barras representam o intervalo de confiança da média (85\%).

\& Wilk (1965), em acordo com Groenvelt et al . (1984), Ball et al. (1988) eRodrigues et al. (2011). Os val ores médios de $\log \mathrm{k}_{\mathrm{a}}$, em todos os tratamentos e para os solos I ell , estão apresentados na figura 8.

No solol, no tratamento C0, observa-se valor de $\log \mathrm{k}_{\mathrm{a}}$ menor que zero (Figura 8); nessa situação, o solo, segundo McQueen \& Shepard (2002), pode ser considerado impermeável. Esses autores afirmam que os poros estão bloqueados e não fazem parte do transporte convectivo do ar quando apresentam $k_{a} \leq$ $1 \mu \mathrm{m}^{2}\left(\log \mathrm{k}_{\mathrm{a}} \leq 0\right)$.

As diferenças significativas entretratamentos no solol ell demonstraram queo estresseaoser aplicado fez com que permeabilidade do solo ao ar diminuísse em consequência da compactação eaumentasse após os ciclos. Essa condição de aumento da permeabilidade ao ar, segundo Dörner et al. (2011), ocorre porque, enquanto os estresses mecânicos diminuem a permeabilidade ao ar como uma consequência da redução de macroporos, o cicl o de secamento per mite que o sol o transporte mais ar a partir da formação de fendas entre os agregados.

A partir da relação da variável permeabilidade do solo ao ar, obteve-se a distribuição dos valores da resiliência física dos solos, cal culados conformeHerrick \& Wander (1998), indicada na figura 9 para mel hor visualização dos dados, mostrandoa variação entre os dois sol os ea amplitude dos valores.

Os resultados demonstram que o sol o argil oso foi altamente resiliente, apresentando diferença significativa em relação à recuperação do sol o francoargilo-arenoso; isso se deve às características de sol os 


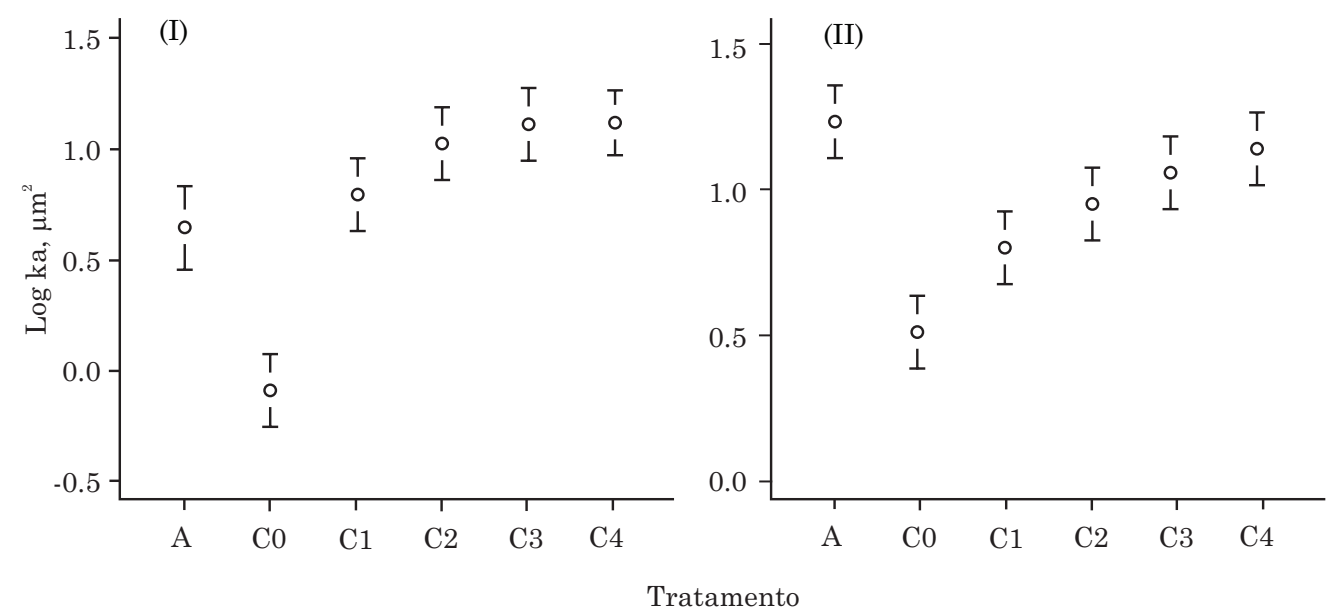

Figura 8. Valores médios de log de permeabilidade ao ar de dois Latossolos Vermelhos distróficos, um argiloso (I) e um franco-argilo-arenoso (II), para os tratamentos A, C0, C1, C2, C3 e C4. As barras representam o intervalo de confiança da média (85\%).

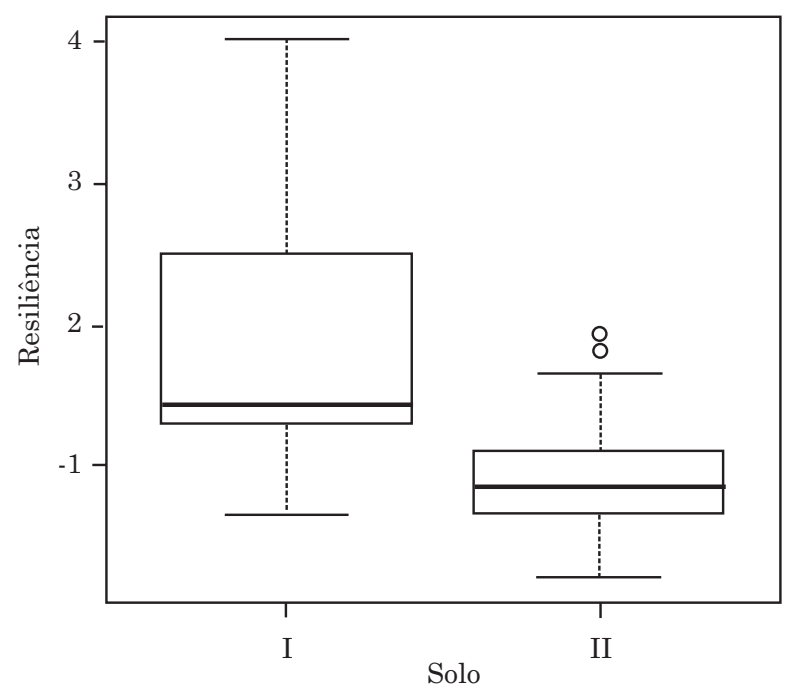

Figura 9. Distribuição dos valores de resiliência da permeabilidade do solo ao ar de dois L atossolos Vermelhos distróficos, um argiloso (I) e um franco-argilo-arenoso (II). As barras representam o intervalo de confiança da média (85\%).

com menor percentagem de argila mais suscetíveis à compactação (Shestak \& Busse, 2005) e com menor capacidade de recuperação (Tobias et al., 2001). No entanto, a recuperação dosololl podeestar relacionada coma presença dematéria orgânica, já observada pelo retorno do vol ume do sol o depois de estresses físi cos e na mudança de manejo (Zhang et al., 2005).

Dörner et al. (2011) também encontraram relação significativa entre a permeabilidade do solo ao ar medida depois do estressecompressivoea recuperação da estrutura do solo, propondo que essa rel ação seja um indicador da resiliência funcional dos poros do solo, já quetransmitea capacidadedosolo derecuperar seu volume inicial de garantir otransportedear, ou seja, a resiliência funcional dos poros aumenta coma recuperação do vol ume do solo, sendo sol os mais bem estruturados e com mai or capacidade de recuperação, devido a uma maior continuidade de poros.

Essa quantificação que relaciona o impacto do manejo sobre as funções dos poros do solo e a sua capacidade para se recuperar (Peth \& Horn, 2006; Gregory et al., 2007, 2009; Dörner et al., 2009) vem, segundo Dörner et al. (2011), de encontro às prioridades atuais, como a mel horia na qual idadedos solos para aumento da produção de alimentos, o controle de tráfego devido ao aumento do peso das máquinas, o qual sujeita o sol o a maiores estresses mecânicos, e a exposição do solo à seca em muitas áreas devido à mudança do clima, principalmente nos trópi cos esubtrópicos, onde o risco de degradação do solo é um problema severo e são raras as informações em relação à recuperação de áreas degradadas e ao impacto econômico na produção (Blanco \& Lal, 2010).

\section{CONCLUSÕES}

1. A estrutura dos dois Latossolos Vermel hos apresenta comportamento dinâmico e muda em consequência da compactação, assi m como dos ciclos de umedecimento e secamento.

2. Os ciclos de umedecimento e secamento contribuem para a recuperação da permeabilidade do soloao ar, mas não o suficiente para a porosidadetotal ea densidade do solo.

3. Sol os argil osos, como o sol ol, apresentam mai or recuperação e são considerados mais resilientes fisicamente que sol os franco-argilo-arenosos, como o sololl. 


\section{LITE RATURA CITADA}

ARAÚJ O, A.G. Estimativa e classificação da compactação do solo pelo tráfego de máquinas agrícolas através da modelagem nebulosa. São Paulo, Escola Politécnica, Universidade de São Paulo, 2004. 224p. (Tese de Doutorado)

ASSIS, R.L. \& LANÇAS, K.P. Avaliação da compressibilidade de um Nitossolo Vermel ho distroférrico sob plantio direto, preparo convencional e mata nativa. R. Bras. Ci. Solo, 29:515-522, 2005.

BALL, B.C.; O'SULLIVAN, M.F. \& HUNTER, R. Gas difusion, fluid flow and derived pore continuity índices in relation to vehicle traffic and tillage. J. Soil Sci., 39:327-339, 1988.

BAUMGARTL, T. \& KÖCK, B. Modeling volume change and mechanical properties with hydraulic models. Soil Sci. Soc. Am. J ., 68:57-65, 2004.

BLAKE, G.R. \& HARTGE, K.H. Bulk density. In: KLUTE, A., ed. Methods of soil analysis; physical and mineralogical methods. 2.ed. Madison, American Society of Agronomy, 1986. p.363-375.

BLANCO, H. \& LAL, R. Soil resilience and conservation. In: BLANCO, H. \& LAL, R., eds. Principles of soil conservation and management. Columbus, Springer Science Business Media B.V., 2010. p.15-33.

BRADY, N. \& WEIL, R.R. The nature and properties of soils. 14th ed. New J ersey: Prentice-Hall, 2007. 980p.

BRADY, N.C. \& WEIL, R.R. The nature and properties of soils. 13.ed. New J ersey, Prentice Hall, 2002. 960p.

CAVIGLIONE, J.H.; KIIHL, L.R.B.; CARAMORI, P.H. \& OLIVEIRA, D. Cartas climáticas do Paraná. Londrina, IAPAR, 2000. CD-ROM.

CHAN, K.Y. Bulk density. In: LAL, R., ed. Encyclopedia of soil science. New York, Marcel Dekker, 2002. p.128-130.

CAVALIERI, K.M.V.; SILVA, A.P.; TORMENA, C.A.; LEÃO, T.P.; DEXTER, A.R. \& HAKANSSON, I. Long-term effects of no-tillage on dynamic soil physical properties in a Rhodic Ferrasol in Paraná , Brazil. Soil Tillage Res., 103:158-164, 2009.

COLLARES, G.L.; REINERT, D.J .; REICHERT, J.M. \& KAISER, D.R. Compactação de um Latossolo induzida pelo tráfego de máquinas e sua relação com o crescimento e produtividade de feijão e trigo. R. Bras. Ci. Solo, 32:933942, 2008.

CORSINI, P.C. \& FERRAUDO, A.S. Efeitos de sistemas de cultivos densidade e macroporosidade do solo e no desenvolvimento radicular do milho em Latossolo roxo. Pesq. Agropec. Bras., 34:289-98, 1999.

DEXTER, A.R. Amelioration of soil by natural processes. Soil Tillage Res., 20:87-100, 1991.

DEC, D.; DÖRNER, J . \& BALOCCHI,O. Temporal and spatial variability of structure dependent properties of a volcanic ash soil under pasture in southern Chile. Chilean J . Agric. Res., 71:293-303, 2011.
DIAS J UNIOR, M.S. \& PIERCE, F.J . O processo de compactação do solo e sua modelagem. R. Bras. Ci. Solo, 20:175-182, 1996.

DÖRNER, J .; DEC, D.; PENG, X. \& HORN, R. Efecto del cambio de uso en la estabilidad dela estructura y la función de los poros de un Andisol (Typic Hapludand) del sur de Chile. R. Ci. Suelo Nutr. Veg., 9:190-209, 2009.

DÖRNER, J .; DEC, D.; ZÚÑIGA, F.; SANDOVAL, P. \& HORN, R. Effect of land use change on Andosol's pore functions and their functional resilience after mechanical and hydraulic stresses. Soil Tillage Res., 115/116:71-79, 2011.

FIGUEIREDO, G.C. Avanços metodológicos e instrumentais em física do solo. Piracicaba, Escola Superior de Agricultura "Luiz de Queiroz", 2010. 163p. (Tese de Doutorado)

FIGUEIREDO, G.C.; SILVA, A.P.; TORMENA, C.A.; GIAROLA, N.F.B.; MORAES, S.O. \& ALMEIDA, B.G. Desenvolvimento de um consolidômetro pneumático: Modelagem da compactação, penetrometria e resistência tênsil de agregados de solo. R. Bras. Ci. Solo, 35:389-402, 2011.

FRANCO, I.; CONTIN, M.; BRAGATO, G. \& DE NOBILI, M. Microbiological resilience of soils contaminated with crude oil. Geoderma, 121:17-30, 2004.

GARDNER, W.H. Water content. In: KLUTE, A., ed. Methods of soil analysis: Physical and mineralogical methods. 2.ed. Madison, American Society of Agronomy, 1986. Part 1. p.493-544.

GEE, G. \& BAUDER, J.W. Particle-size analysis. In: KLUTE, A., ed. Methods of soil analysis. 2.ed. Madison, ASA/SSSA, 1986. Part 1. p.383-411. (Agronomy Monograph, 9)

GIAROLA, N.F.B.; BRACHTVOGEL, E.L.; FONTANIVA, S., PEREIRA, R.A. \& FIOREZE, S.L. Cultivares de soja sob plantio direto em Latossolo Vermelho compactado. Acta Sci. Agron., 31:641-646, 2009.

GREGORY, A.S.; WATTS, C.W.; WHALLEY, W.E.; KUAN, H.L.; GRIFFITHS, B.S.; HALLET, P.D. \& WHITMORE, A.P. Physical resilience of soil to field compaction and the interactions with plant growth and microbial community structure. Eur. J . Soil Sci., 58:1221-1232, 2007.

GREGORY, A.S.; WATTS, C.W.; GRIFFITHS, B.S.; HALLET, P.D.; KUAN, H.L. \& WHITMORE, A.P. The effect of long-term soil management on the physical and biological resilience of a range of arable and grassland soils in England. Geoderma, 153:172-185, 2009.

GRIFFITHS, B.S.; RITZ, K.; BARDGETT, R.D.; COOK, R.; CHRISTENSEN, S.; EKELUND, F.; SORENSEN, S.J .; BAATH, E.; BLOEM, J .; DE RUITER, P.C.; DOLFING, J . $\&$ NICOLARDIT, B. E cosystem response of pasture soil communities to fumigation-induced microbial diversity reductions; an examination of the biodiversity-ecosystem function relantionship. Oikos, 90:279-294, 2000.

GROENVELT, P.H.; KAY, B.D. \& GRANT,C.D. Physical assessment of soil with respect to rooting potential. Geoderma, 34:101-114, 1984. 
HÅKANSSON, I.; VOORHEES, W.B. \& RILEY, H. Vehicle and wheel factors influencing soil compaction and crop responses in different traffic regimes. Soil Tillage Res., 11:239-282, 1988.

HÅKANSSON, I. \& MEDVEDEV, V.W. Protection of soils from mechanical overloading by establishing limits for stresses caused by heavy vehicles. Soil Tillage Res., 35:8597, 1995.

HÅKANSSON, I. Machinery-induced compaction of arable soils: Incidence, consequences, counter-measures. Sweden, Dept, of Soil Sciences, Division of Soil Management, Uppsala, 2005. 153p.

HERRICK, J.E. \& WANDER, M.M. Relationships between soil organic carbon and soil quality in cropped and ragel and soils: The importance of distribution, composition and soil biological activity. In: LAL, R.; KIMBLE, J .M.; FOLLET, R.F. \& STEWART, B.A., eds. Soil processes and carbon cycle: Advances in soil science. Boca Raton, CRC Press, 1998. p.405-426.

HORN, R. \& BAUMGARTL, T. Dynamic properties of soils. In: WARRICK, A.W., ed. Soil physics companion. Boca Raton, CRC Press, 2002. p.17-48.

KLEIN, V.A. \& BOLLER, W. Avaliação de diferentes manejos de solo e métodos de semeadura em áreas sob sistema plantio direto. Ci. Rural, 25:395-398, 1995.

$L A L, R$. Tillage effects on soil degradation, soil resilience, soil quality, and sustainability. Soil Tillage Res., 27:1-8, 1993.

$L A L, R$. Sustainable land use systems and soil resilience. In: GREENLAND, D.J . \& SZABOLCS, I., eds. Soil resilience and sustainable land use. Wallingford, CAB I nternational, 1994. p.41-67.

LIBARDI, P.L. Dinâmica da água no solo. São Paulo, EDUSP, 2005. 335p.

MCBRIDE, R.A. \& WATSON, G.C. An investigation of reexpansion of unsaturated, structured soils during cycles static loading. Soil Tillage Res., 17:241-253, 1990.

McQuEEN, D.J . \& SHEPHERD, T.G. Physical changes and compaction sensitivity of a fine-textured, poorly drained soil (Typic Endoaquept) under varying durations of cropping, Manawatu Region. Soil Tillage Res., 25:217230, 2002.

PAYTON, M.E.; MILLER, A.E. \& RAUN, W.R. Testing statistical hypothesis using standard error bars and confidence intervals. Commun. Soil Sci. Plant Anal., 31:547-551, 2000.

PETH, S. \& HORN, R. The mechanical behavior of structured and homogenized soil under repeated loading. J. Plant Nutr. Soil Sci., 169:401-410, 2006.

REICHARDT, K.; DOURADO-NETO,D.; TIMM, L.C.; BASANTA, M.V.; CAVALCANTE, L.F.; TERUEL, D.A.; BACCHI, SANTOS, O.O.; TOMINAGA, T.T.; CERRI, C.C. \& TRIVELIN, P.C.O. Management of crop residues for sustainable crop production. IAEA-TECDOC, 1354:149169, 2003.
REICHERT, J .M.; SUZUKI , L.E.A.S.; REINERT, D.J .; HORN, R. \& HAKANSSON, I. Reference bulk density and critical degree-of-compactness for no-till crop production in subtropical highly weathered soils. Soil Tillage Res., 102:242-254, 2009.

RODRIGUES, S.; DA SILVA, A.P.; GIAROLA, N.F.B. \& ROSA, J.A. Permeabilidade ao ar em Latossolo Vermel ho sob diferentes sistemas de manejo. R. Bras. Ci. Solo 35:105114. 2011.

ROSA, D.P.; REICHERT, J .M.; SATTLER, A.; REINERT, D.J .; MENTGES, M.I. \& VIEIRA, D.A. Esforços e mobilização provocada pela haste sulcadora de semeadora, em Latossolo escarificado em diferentes épocas. Pesq. Agropec. Bras., 43:396-400, 2008.

ROSEBERG, R.J . \& MCCOY, E.L. Measurement of soil macropore air permeability. Soil Sci. Soc. Am. J ., 54:969974, 1990.

SEYBOLD, C.A.; HERRICK, J.E. \& BREJDA, J.J. Soil resilience: $A$ fundamental component of soil quality. Soil Sci., 164:224-234, 1999.

SHAPIRO, S.S. \& WILK, M.B. Analysis of variance test for normality (complete samples). Biometrika. 52:591-611, 1965.

SHESTAK, C.J . \& BUSSE, M.D. Compaction alters physical but not biological indices of soil health. Soil Sci. Soc. Am. J., 69:236-246, 2005.

SILVA, A.P.; LIBARDI, P.L. \& CAMARGO, O.A. Influência da compactação nas propriedades físicas de dois Latossolos. R. Bras. Ci. Solo, 10:91-95, 1986.

SILVA, V.R.; REINERT, D.J . \& REICHERT, J.M. Susceptibilidade à compactação de um Latossolo Vermelho escuro e de um Podzólico Vermelho-Amarelo. R. Bras. Ci. Solo, 24:239-249, 2000.

SILVA, R.B.; DIAS J UNIOR, M.S.; SANTOS, F.L. \& FRANZ, C.A.B. Influência do preparo inicial sobre a estrutura do solo quando da adoção do sistema plantio direto, avaliada por meio da pressão de preconsolidação. R. Bras. Ci. Solo, 27:961-971, 2003.

SILVEIRA, P.M.; STONE, L.F.; ALVES J ÚNIOR J . \& SILVA, J.G. Efeitos do manejo do solo sob plantio direto e de culturas na densidade e porosidade de um Latossolo. Biosci. J ., 24:53-59, 2008.

SPRINGER, D.S.; CULLEN, S.J . \& EVERETT, L.G. Laboratory studies on air permeability. In: EVERETT, L.G. \& CULLEN, S.J., eds. Handbook of vadose zone characterization and monitoring. Boca Raton, Lewis Publishers, 1995. p.217-248.

STRECK, C.A.; REINERT, D.J .; REICHERT, J .M. \& KAISER, D.R. Modificações em propriedades físicas com a compactação do solo causada pelo tráfego induzido de um trator em plantio direto. Ci. Rural, 34:755-760, 2004.

TOBIAS, S.; HENNES, M.; MEIER, E. \& SCHULIN, R. Estimating soil resilience to compaction by measuring changes in surface and subsurface levels. Soil Use Manage., 17:229-234, 2001. 
TORMENA, C.A.; ROLLOF, G. \& SÁ, J .C.M. Propriedades físicas do sol o sob plantio direto influenciadas por calagem, preparo inicial e tráfego. R. Bras. Ci. Solo, 22:301-309, 1998.

VEZZANI, F.M. Qualidade do sistema solo na produção agrícola. Porto Alegre, Universidade Federal do Rio Grande do Sul, 2001. 184p. (Tese de Doutorado)
WARRICK, A.W. Spatial variability. In: HILLEL, D., ed. Environmental soil physics. New York, Academic Press, 1998. p.655-675.

ZHANG, B.; HORN, R. \& HALLET, P.D. Mechanical resilience of degraded soil amended with organic matter, Soil Sci. Soc. Am. J ., 69: 864-871, 2005. 